\title{
Effect of fetal echocardiography on postnatal survival: Single center 2 years experience
}

\author{
Fetal ekokardiyografinin postnatal sağkalım üzerine etkisi: \\ Tek merkez 2 yıllık deneyim
}

\author{
Öykü TOSUN $\odot$
}

ABSTRACT

\begin{abstract}
Aim: Cardiac anomalies occur in about 1\% of newborns and form the most common group of congenital anomalies. Congenital heart diseases (CHDs)are the most common cause of early neonatal deaths due to congenital anomalies.
\end{abstract}

Methods: A total of 152 pregnant women who referred for fetal echocardiographic evaluation between 2014 and 2016 were reviewed retrospectively from the pediatric cardiology outpatient clinic records.

Results: Sixteen pregnancies were diagnosed with complex CHD. For all fetuses diagnosed with complex CHD, and scheduled for intervention and surgery the families and the congenital heart intervention center that will performed the interventions for fetuses were interviewed during prenatal period, and the delivery was coordinated with a multidisciplinary approach. Sixteen fetuses were diagnosed with 4 had aortic coarctation $(n=4)$, tetralogy of Fallot $(n=5)$, Fallot tetralogy without pulmonary valve $(n=1)$, hypoplastic left heart syndrome $(n=2)$, transposition of great arteries $(n=2)$, and double- inlet left ventricle $(n=2)$. In our study, all of the patients who needed postpartum emergency interventional treatment were planned, and the center was set up during the prenatal period, then the patients were referred by starting PGE1 treatment during the postnatal period. The fetuses that may need urgent intervention in the delivery room were directed to the center during the prenatal period. No hemodynamic instability occurred in patients during and after birth.

Conclusion: The prenatal diagnosis of $\mathrm{CHD}$ and postnatal risk determination, can reduce the neoanatal mortality significantly because it allows the interventional treatment to be coordinated with the center.

Keywords: Fetal, postnatal, survival
Öz

\begin{abstract}
Amaç: Yenidoğanlarda kalp anomalileri yaklaşık \%1 oranında görülmekte olup, en sık rastlanan doğumsal anomali grubunu oluştururlar. Doğumsal kalp hastalıkları (DKH) anomaliye bağlı erken yenidoğan ölümlerin de en sık görülen nedeni doğumsal kalp hastalıklarıdır (DKH).
\end{abstract}

Yöntem: 2014- 2016 tarihleri arasında Çocuk Kardiyoloji Polikliniğine fetal ekokardiyografik değerlendirme yapılmak üzere yönlendirilen 152 gebeye ait veriler çocuk kardiyoloji poliklinik kayıtlarından retrospektif olarak incelendi.

\begin{abstract}
Bulgular: On altı gebelikte kompleks doğumsal kalp hastalığı tanısı kondu. Kompleks doğumsal kalp hastalığı tanısı koyulan tüm fetüslerden girişim ya da cerrahi müdahale ön görülen fetüsler için aile ile görüşülerek müdahale yapılacak merkez ile prenatal dönemde görüşüldü ve doğumların multidisipliner bir yaklaşımla koordine olarak yapılması sağlandı. On altı fetusdan 4 tanesi aort koarktasyonu (AK), 5 tanesi Fallot tetralojisi (TOF), 1 tanesi fallot pulmoner kapak yokluğu (TOF-APV), 2 tanesi hipoplastik sol kalp sendromu (HLHS), 2 tanesi büyük arter transpozisyonu (BAT), 2 tanesi çift girişli sol ventrikül (DILV) tanısı aldı. Çalışmamızda, doğum sonrası acil girişimsel tedavi gerekecek hastaların tamamında planlama ve merkezin ayarlanması prenatal dönemde yapılmış olup, hastalar postnatal dönemde PGE1 başlanarak sevk edilmiştir. Doğum salonunda acil girişim gereksinimi olabilecek fetuslar bu girișimin yapılabileceği merkezlere anne karnında yönlendirilmiştir. Doğum sırasında ve sonrasında hastalarda hiçbir hemodinamik instabilite meydana gelmemiştir.
\end{abstract}

Sonuç: Doğumsal kalp hastalıklarının prenatal dönemde tanı alması postnatal risk belirlenmesi, girişimsel tedavi olacak merkezle koordine olunabilmesine olanak sağladığından neoanatal mortaliteyi önemli ölçüde azaltmaktadır.

Anahtar kelimeler: Fetal, postnatal, sağ kalım

Received: 28.05 .2018

Accepted: 13.06 .2018

Istanbul Medeniyet University, Department of Pediatric Cardiology, Istanbul, Turkey

Yazışma adresi: Öykü Tosun, Istanbul Medeniyet University, Department of Pediatric Cardiology, Istanbul, Turkey

e-mail: isaltosun@hotmail.com

Yazarın ORCiD bilgileri:

Ö.T. 0000-0003-1031-273X 


\section{Giriş}

Doğumsal kalp hastalıkları tüm canlı doğumların \%1'inde görülmekte olup, en sık rastlanan doğumsal hastalık grubunu oluşturur ${ }^{1}$. Doğumsal kalp hastalıkları (DKH) erken yenidoğan dönemindeki ölümlerin en sık nedenidir². Gerekli tıbbi ve/veya cerrahi tedavinin planlanması için DKH'larının erken tanınması yaşamsal önem taşımaktadır³. DKH'larının erken tanı alabilmesi fetal ekokardiyografi ile olasıdır. Fetal ekokardiyografi yapılması için fetal, maternal veya kalıtsal nedenlerden herhangi birine sahip gebeler yüksek risk grubu olarak kabul edilirler ancak bunların dışında düşük risk kabul edilen çeşitli nedenler ile de fetal ekokardiyografi yapılabilmektedir ${ }^{4-6}$. Fetal ekokardiyografi, fetal, maternal veya kalıtsal nedenlerden herhangi birine sahip yüksek risk grubundaki gebelere uygulandığı gibi düşük risk kabul edilen gebelere de çeşitli nedenler ile uygulanabilmektedir ${ }^{6}$. Fetal ekokardiyografi en uygun zaman 18-22. gestasyon haftası $(\mathrm{GH})$ olmasına rağmen, gerekli hallerde daha erken ve daha geç gebelik haftalarında yapılabilmektedir. Yıllar içerisinde fetal ekokardiyografik görüntülemedeki olumlu gelişmeler DKH'larında tanı oranının artmasını sağlamıştır ${ }^{4}$. Fetusun postnatal yaşama adaptasyonunu içeren fetal-neonatal dolaşım geçişi oldukça önemlidir. Kompleks DKH'larında fetal tanı bu geçiş döneminde hemodinamik instabiliteyi önleyecek, özellikli postnatal bakım planlanmasında son derecede önemlidir ${ }^{7}$. Aynı zamanda yapısal kardiyak patoloji görülmeyen fetüslarda fetal aritmi gelişebilmektedir. Fetal aritmilerin çoğu bening karakterde olmasına rağmen, sürekli aritmiler ve bloklar düşük kardiyak debi sonucu non-immun hidrops fetalis gelişimine ve fetal kayıplara neden olabilir ${ }^{8,9}$. Bu tür aritmilerin erken tanınması ve doğru tedavisi hem intrauterin kayıpların ve postnatal mortalitenin önlemmesine hem de doğum şekli, yeri ve zamanlaması ile ilgili karar verilebilmesine olanak sağlamaktadır. Bu çalışmanın amacı, fetal ekokardiyografinin DKH'larının prenatal dönemde tanınmasınındaki ve postnatal hemodinamik süreç üzerine etkisinin önemini vurgulamaktır.

\section{GEREÇ ve YÖNTEM}

Mart 2014-Ocak 2016 tarihleri arasında Çocuk Kardiyoloji Polikliniğine fetal ekokardiyografik değerlendirme yapılmak üzere yönlendirilen 152 gebeye ait veriler çocuk kardiyoloji poliklinik kayıtlarından retrospektif olarak incelendi. Çalışma hastanemiz Etik Kurulundan 2018/0134 numaralı etik kurul onayı alınarak yapılmıştır. Fetal ekokardiyografik çalışma yapılırken gebelerin yaşları ortalama $34 \pm 8,2$ yıl, gestasyon haftaları ortalama $22 \pm 1,3$ hafta idi. Fetal ekokardiyografi için yönlendirilme endikasyonları, 132 gebede rutin obstetrik incelemede fetal kalp görüntülemesi yapılamaması, 6 gebede apikal dört boşluk görüntülemede sorun saptanması, 4'ünün doğumsal kalp hastalığı ön tanısı alması, 20 hasta fetal kalp atımlarında sorun izlenmesi idi. Fetal ekokardiyografik çalışma tek bir pediyatrik kardiyolog tarafından Samsung H60 Echocardiography Sistemi (Samsung Healtcare) konveks prob ile yapıldı. Çalışma retrospektif olduğu için ve hastalara uygulanmış ve raporlamış rutin fetal ekokardiyografik veriler tarandığı için bilgilendirilmiş onam formu alınmadı.

\section{BULGULAR}

Fetal ekokardiyografik görüntüleme yapılan toplam 152 gebenin yaşları ortalama $34 \pm 8,2$ yıl, gestasyon haftaları ortalama $22 \pm 1,3$ hafta idi. Gebelerden 22 adedinde akraba evlililiği, 8'inde önceki gebeliğinde DKH bulunmakta idi. Gebelerden 6'sı gebelik süresince ve öncesinde sigara kullanmakta idi.

On iki fetüsde $(\% 7,8)$ küçük müsküler ventriküler septal defekt (VSD), 4 fetüsde perimembranöz VSD, 1 fetüsde parsiyel pulmoner venöz dönüş anomalisi (PAPVD), 1 fetüsde sol atriyal izomerizm izlendi.

On altı gebede $(\% 10,52)$ kompleks DKH tanısı aldı. Kompleks DKH saptanan gebelerin 6'sı apikal dört boşluk görüntülemede sorun olduğu için, $\sigma^{\prime}$ sı kalp görüntülemesi hiç yapılamadığı için, 4'ü DKH ön tanıSı aldığı için fetal ekokardiyografi için yönlendirilmişti. DKH tanısı alan fetüslerin hiçbirinde ileri yaş anne gebeliği ve anneye ait başka bir risk faktörü bulunmu- 
yordu. Kompleks DKH tanısı alam tüm fetüslerden, girişim ya da cerrahi müdahale ön görülen fetüsler için aile ile görüşülerek müdahale yapılacak merkez ile prenatal dönemde görüşüldü ve doğumların multidisipliner bir yaklaşımla koordine olarak yapılması sağlandı. Gebeliklerden 12'si farklı endikasyonlardan sezaryen doğumla, 3'ü normal vajinal yol ile termde sonlandırıldı. Bir fetüs halen takip edilmektedir ${ }^{16}$. Fetüsden 4 tanesi aort koarktasyonu (AK), 5 tanesi Fallot tetralojisi (TOF), 1 tanesi fallot pulmoner kapak yokluğu sendromu (TOF-APV), 2 tanesi hipoplastik sol kalp sendromu (HLHS), 2 tanesi büyük arter transpozisyonu (BAT), 2 tanesi çift girişli sol ventrikül (DILV) tanısı aldı (Tablo 1). DKH'ı tanısı postnatal yapılan ekokardiyografik çalışma ile doğrulandı. AK tanısı alan 4 hastadan 1 tanesi hafif düzeyde olduğu için postnatal herhangi bir müdahale yapılmadan taburcu edilerek takibe alındı. Önemli AK tanılı 3 hastaya postnatal prostaglandin E1 (PGE1) infüzyonu başlandı ve postanatal 2. günde cerrahi merkeze yönlendirildi. TOF tanısı almış olan hastaların hiçbiri duktus bağımlı olmadığı için postnatal anne yanında takip edildi ve 12 . ayda tam düzeltme ameliyatı yapılması planlanarak poliklinik takibine alındı. Bir hastada TOF-APV tanısı fetüs halen takip edilmektedir. İki adet prenatal dönemde tanı alan HLHS' lu fetüsden birinde aile terminasyon istediği için perinatoloji kliniğine terminasyon için yönlendirildi. Diğeri cerrahi operasyon geçireceği özel bir merkeze ailenin isteği üzerine yönlendirildi. Kliniğimizde 2 adet BAT fetal dönemde tanı aldı. Bunlardan 1 tanesinde 36. GH'da interatriyal septumda restriksiyon gelişmesi üzerine postnatal acil balon septostomi ve cerrahi operasyon yapılacağı merkezde doğum yapması için yönlendirildi. Diğer hasta doğum kliniğimizde gerçekleşti ve

Tablo 1. Fetal ekokardiyografi ile belirlenen doğumsal kalp hastalıkları.

\begin{tabular}{lll}
\hline Kardiyak Tanı & Sayı (16) & \% \\
\hline Aort Koarktasyonu & 4 & 25 \\
Fallot Tetralojisi & 5 & 31.25 \\
Fallot Pulmoner Kapak Yokluğu & 1 & 6.25 \\
Hipoplastik Sol Kalp Sendromu & 2 & 12.5 \\
Büyük Arter Transpozisyonu & 2 & 12.5 \\
Çift Girişli Sol Ventrikül & 2 & 12.5 \\
\hline
\end{tabular}

postnatal PGE1 başlanarak 2. gün Jaten operasyonu yapılmak üzere cerrahi merkeze sevk edildi. DILV tanısı alan 2 hastada uzun segment aort koarktasyonu eşlik ettiği için postnatal PGE1 infüzyonu başlanarak palyatif switch operasyonu için cerrahi merkeze sevk edildi. Kliniğimizde 21-24. GH'da 10 fetüsden 5'inde hidrops fetalis gelişmemiş sürekli kısa ventrikuloatriyal (VA) intervalli supraventriküler taşikardi (SVT), 5 'inde non-immun hidrops fetalis gelişmiş sürekli uzun VA intervalli SVT belirlendi. Intrauterin antiaritmik tedavi başlandı ve hepsi postnatal normal sinüs ritminde doğdu, postnatal aritmi izlenmedi ve sorunsuz takip edilmekteler.

\section{TARTIŞMA}

Kompleks DKH'larının prenatal olarak tanınması postnatal yönetimin planlanmasında oldukça önemlidir. Fetal ekokardiyografi için endikasyonu olan gebeler çocuk kardiyoloji kliniğine yönlendirilmektedir. Akraba evliliği ve ileri yaş anne gebeliği pek çok konjenital anomali gibi DKH'ları içinde risk faktörü olmasına rağmen, çalışmamızda akraba evliliği olan hiçbir fetüsde DKH saptanmaması sayının az olmasına bağlı olabilir.

Gelişmiş ülkelerde yapılan birkaç çalışmada, DKH'larının prenatal tanısının postnatal sonuçlar üzerine olumlu etkisine dikkat çekmektedir ${ }^{10,11}$. Changlanı ve ark.'nın ${ }^{12}$ yaptığı çalışmada prenatal dönemde tanı alan kompleks DKH'larında cerrahi merkeze sevk ortalama postnatal 2. günde gerçekleşmiş ve postnatal kısa dönem sağ kalım oranı \% 90 olarak bildirilmiştir. Çalışmamızda, postnatal kısa dönem sağkalım $\% 100$ 'dür ve tüm hastalar en geç postnatal ikinci günde, bir kısmı ise intrauterin dönemde girişimsel tedavi olacağı merkeze yönlendirilmiştir. Benzer şekilde Mary ve ark.'nın ${ }^{13}$ yaptığı çalışmada, prenatal tanının ve risk belirlenmesinin postnatal mortalite üzerine etkisine dikkat çekilmiştir. Yapılan birkaç çalışmada, fetal ekokardiyografinin deneyimli ellerde yapılması kadar prenatal dönemde DKH tanısı alan fetüslerde koordinasyonun intrauterin dönemde yapılmasının, doğum yeri ve zamanlamasının planlanmasının postnatal sonuçları üzerine olumlu etkisine dikkat 
çekilmektedir ${ }^{14-16}$. Çalışmamızda, doğum sonrası acil girişimsel tedavi gerekecek hastaların tamamında planlama ve merkezin ayarlanması prenatal dönemde yapılmış olup, hastalar postnatal dönemde PGE1 başlanarak sevk edilmiştir. Doğum salonunda acil girişim gereksinimi olabilecek fetüsler bu girişimin yapılabileceği merkezlere anne karnında yönlendirilmiştir. Doğum sırasında ve sonrasında hastalarda hiçbir hemodinamik instabilite meydana gelmemiştir.

Fetal aritmilerin çoğu bening karakterde olmasına rağmen, sürekli aritmiler ve bloklar düşük kardiyak debi sonucu non-immun hidrops fetalis gelişimine ve fetal kayıplara neden olabilir ${ }^{8,9}$. Doğru ve zamanında tanı ve tedavi ile intrauterin kayıpların önlenmesinin olası olduğunu gösteren çalışmalar vardır ${ }^{8,9}$. Bizim çaIışmamızda da, hidrops fetalisle gelen fetüslerde dahil olmak üzere tüm fetüslerde farklı antiaritmiklerle normal sinüs ritmi sağlanmış ve hidrops bulguları gerilemiştir.

\section{Kısıtlamalar:}

Çalışmamız retrospektif bir çalışma olduğu için veriler kısıtlıdır. Hastaların uzun dönem sonuçları için daha fazla hasta ve daha uzun izlem süresine gereksinim vardır.

\section{SONUÇ}

DKH'larının prenatal dönemde tanı alması postnatal risk belirlenmesi, girişimsel tedavi olacak merkezle koordine olunabilmesine olanak sağladığından neoanatal mortaliteyi önemli ölçüde azaltmaktadır.

\section{KAYNAKLAR}

1. Reller MD, Strickland MJ, Riehle-Colarusso T, Mahle WT, Correa A. Prevalence of congenital heart defects in metropolitan Atlanta, 1998-2005. J Pediatr. 2008;153:807-813. Epub 2008 Jul 26. PubMed PMID: 18657826; PubMed Central PMCID: PMC2613036.

https://doi.org/10.1016/j.jpeds.2008.05.059

2. Athews TJ, MacDorman MF. Infant mortality statistics from the 2010 period linked birth/infant death data set. Natl Vital Stat Rep. 2013;62:1-26.
3. Vaidyanathan B, Kumar RK. The Global burden of congenital heart disease. Congenital Cardiology Today. 2005;3:1-8.

4. Dev Maulik, Navin C. Nanda, Devika Maulik, Gustavo Vilchez. A brief history of fetal echocardiography and its impact on the management of congenital heart disease. Echocardiography. 2017;34:1760-7. https://doi.org/10.1111/echo.13713

5. Ece I, Epçaçan S, Üner A, Ceylan N, Demir N, Aydın I. Fetal Ekokardiyografi Yapılan Hastalarımızın Özellikleri ve Postnatal Ekokardiyografi ile Prenatal Tanı Doğruluğunun Araştırılması. Van Tıp Dergisi. 2015;22:96-9.

6. Alp H, Karaarslan S, Baysal T, Karataylı R, Varan B. Riskli Gebeliklerde Fetal Ekokardiyografide Tespit Edilen Yapısal Kalp Hastalıklarının Dağılımı. Selcuk Tıp Derg. 2013;29:113-6.

7. Donofrio MT, Moon-Grady AJ, Hornberger LK, Copel J, Sklansky M, Abuhamad A. Diagnosis and treatment of fetal cardiac disease: a scientific statement from American Heart Association. Circulation. 2014;129:2183-2242.

https://doi.org/10.1161/01.cir.0000437597.44550.5d

8. Kleiman CS, Nehgme RA. Cardiac arrhythmias in the human fetus. Pediatr Cardiol. 2004;25:234-51.

9. Van Engelen AD, Weijtens O, Brenner JI, Kleinman CS, Copel JA, Stoutenbeek P, Meijboom EJ. Management outcome and follow-up of fetal tachycardia. J Am Coll Cardiol. 1994;24:1371-5. https://doi.org/10.1016/0735-1097(94)90122-8

10. Bonnet D, Coltri A, Butera $G$, et al. Detection of transposition of the great arteries in fetuses reduces neonatal morbidity and mortality. Circulation. 1999;99:916-8. https://doi.org/10.1161/01.CIR.99.7.916

11. Tzifa A, Barker C, Tibby SM, Simpson JM. Prenatal diagnosis of pulmonary atresia: Impact on clinical presentation and early outcome. Arch dis Child Fetal Neonatal ED. 2007;92:199203. https://doi.org/10.1136/adc.2006.093880

12. Changlanı TD, Jose A, Sudhakar A, et al. Outcomes of Infants with Prenatally Diagnosed Congenital Heart Disease Delivered in a Tertiary-care Pediatric Cardiac Facility. Indian Pediatrics. 2015;52:852-6. https://doi.org/10.1007/s13312-015-0731-x

13. Mary T Donofrio, Kami Skurow-Todd, RNC-NIC, et al. RiskStratified Postnatal Care of Newborns with Congenital Heart Disesase Determined by Fetal Echocardiography. Journal of the American Society of Echocardiography. 2015;11:133949. https://doi.org/10.1016/j.echo.2015.07.005

14. Morris SA, Ethen MK, Penny DJ, et al. Prenatal diagnosis, birth location, surgical center, and neonatal mortality in infants with hypoplastic left heart syndrome. Circulation. 2014;129:285-92. https://doi.org/10.1161/CIRCULATIONAHA.113.003711

15. Divanovic A, Hor K, Cnota J, Hirsch R, Kinsel-Ziter M, Michelfelder E. Prediction and prenatal management of severely restrictive atrial septum in fetuses with critical left heart obstruction: clinical experience using pulmonary venous Doppler analysis. J Thorac Cardiovasc Surg. 2011;141:998-94. https://doi.org/10.1016/j.jtcvs.2010.09.043

16. Michelfelder E, Gomez C, Border W, et al. Perinatal management of fetal cardiac anomalies in a specialized obstetricpediatrics center. Am J Perinatol. 2001;18:363-71. https://doi.org/10.1055/s-2001-18696 